\title{
APORTE DE SEDIMENTOS NO RIO TELES PIRES: AMBIENTE DE CONFLUÊNCIA ENTRE O RIO MATRINXÃ NO MUNICÍPIO DE NOVA CANAÃ DO NORTE/MATO GROSSO
}

\author{
Bruna da Cruz Andrade ${ }^{(a)}$, Claudete Silveira Damas Machado ${ }^{(b)}$ Luana Rodrigues de Carvalho ${ }^{\text {(c) }}$ \\ Leila Nalis Paiva da Silva Andrade ${ }^{(d)}$ \\ (a) Acadêmica do Curso de Licenciatura em Geografia da Universidade do Estado de Mato Grosso/Campus de \\ Colider. Bolsista de Iniciação Científica/FAPEMAT. Email: bruna.c.andrade@live.com \\ (b) Acadêmica do Curso de Licenciatura em Geografia da Universidade do Estado de Mato Grosso/Campus de \\ Colider. Bolsista de Iniciação a Docência/PIBID. Email: klaudete_machadotnn@ @hotmail.com \\ (c) Acadêmica do Curso de Licenciatura em Geografia da Universidade do Estado de Mato Grosso/Campus de \\ Colider. Bolsista de Iniciação Científica/PROBIC/UNEMAT. Email: Lunas2.rc@ gmail.com \\ ${ }^{(d)}$ Doutoranda em Ecologia e Recursos Naturais pela Universidade Federal de São Carlos. Professora Assistente do \\ Curso de Geografia da Universidade do Estado de Mato Grosso. Coordenadora do Laboratório de Pesquisa e Ensino \\ em Geomorfologia Fluvial "AntonioChristofoletti”. Coordenadora de área Geografia/Colider do Programa \\ Institucional de Bolsa de Iniciação à Docência (PIBID/CAPES). E-mail: leilaandrade@unemat.br
}

\section{EIXO: BACIAS HIDROGRÁFICAS E RECURSOS HÍDRICOS: ANÁLISE, PLANEJAMENTO E GESTÃO}

\begin{abstract}
Resumo
O rio Matrinxã está localizado $10^{\circ} 59^{\prime} 31.4^{\prime \prime}$ sul e $55^{\circ} 50^{\prime} 29.96^{\prime \prime}$ oeste no município de Nova Canaã do Norte/Mato Grosso. O presente trabalho teve como objetivo quantificar a composição granulométrica dos sedimentos de fundo no ambiente de confluência com o rio Teles Pires. A metodologia constituiu em levantamento bibliográfico; coleta de sedimentos e análise em laboratório. Foram utilizados para mensurar as variáveis hidrodinâmicas: ecobatímetro (profundidade), molinete fluviométrico (velocidade), trena (largura do afluente) e a ferramenta software do googleearth para verificar a largura do rio Teles Pires. Para coleta de sedimentos de fundo foi utilizado a draga (van ven). Em laboratório foi usado o método de pipetagem e peneiramento para caracterizar porcentagens de areia, argila e silte das amostras coletadas. Nos pontos monitorados foram registradas as percentagens de areia (média e fina), argila e silte. $\mathrm{O}$ estudo mostrou a caracterização dos sedimentos e sua distribuição no ambiente fluvial.
\end{abstract}

Palavras chave:Aporte de sedimentos; ambiente de confluência; Rio Teles Pires.

\section{Introdução}

Os rios constituem os agentes mais importante no transporte dos materiais intemperizados das áreas elevadas para as mais baixas e dos continentes para o mar. Sua importância e capital entre todos os processos morfogenético (CHRISTOFOLETTI, 1980).

Segundo Cunha (2013) "A geomorfologia fluvial engloba o estudo dos cursos de água e o das bacias hidrográficas. Enquanto o primeiro se detém nos processos fluviais e nas formas resultantes do 
escoamento das águas, o segundo considera as principais características das bacias hidrográficas que condicionam o regime hidrológico".

Os rios possuem sua própria dinâmica (erosão, transporte e deposição) do material detrítico. O transporte de sedimentos é um processo natural, é o principal elemento modelador das paisagens, que por sua vez pode ser acelerado pela ação antrópica desordenada principalmente junto as margens. As alterações mais danosas ao meio ambiente são a retirada de vegetação, o manejo inadequado do solo e a urbanização (BARTELLI 2012 apud SCAPIN, 2005).

De acordo com Feitosa e Santos (2015) são de extrema importância os estudos em ambientes fluviais, uma vez que ao identificar os principais fatores que contribuem com mudanças no ecossistema e propor medidas para a sua manutenção, uma vez que ao pesquisar a dinâmica de um sistema e conhecer o comportamento dos corpos hídricos pode-se "protegê-los".

Segundo pesquisas da EPE (2008) o rio Teles Pires é o divisor territorial dos estados de Mato Grosso e do Pará no trecho compreendido entre a sua foz, no rio Tapajós, até a foz do rio Paranaíta, um dos seus afluentes pela margem esquerda. A partir deste ponto, até sua nascente, o rio encontra-se inserido no Estado de Mato Grosso. A sua extensão total é de 1.482,00 km, nascendo na serra Azul, a uma altitude média de 800 m, e desenvolve-se no sentido SE-NW até a confluência com o rio Tapajós, a uma altitude aproximada de $95 \mathrm{~m}$.

Trabalhos como os de Leandro et al. (2014) Sedimentos de fundo e em suspensão no corredor fluvial do rio Paraguai, Pantanal Norte Mato-Grossense, Brasil. Silva e Souza (2012) Aporte de Sedimentos do Rio Paraguai no Trecho entre o furado do Touro e passagem velha- Cáceres- MT. Leandro e Sousa (2012) Aporte de sedimentos em feição Morfológica no corredor fluvial do rio Paraguai, Cáceres-MT.

A pesquisa teve como objetivo quantificar a composição granulométrica dos sedimentos de fundo no ambiente de confluência do rio Matrinxã, afluente da margem esquerda do rio Teles Pires no município de Nova Canaã do Norte/Mato Grosso.

\section{Metodologia}

Para o desenvolvimento desta pesquisa realizou-se levantamento bibliográfico em livros, artigos e dentre outros (LUNA, 1999 apud QUARESMA, 2005).

Foi realizado em campo para o reconhecimento e observação da área. A pesquisa ocorreu no período de cheia do ano de 2015. Foram coletados sedimentos de fundo e quantificados a batimetria em dois pontos do ambiente fluvial. 
Para mensurar a profundidade foi utilizada o ecobatimetro Garmin 350 e para calcular a velocidade utilizou-se o molinete fluviométrico. Para medir a largura do afluente foi utilizada trena de $50 \mathrm{~m}$ e a ferramenta software do Google Earth para verificar a largura do rio Teles Pires.

Foi utilizada a draga van vem Petersen (amostrador de Mandíbulas) para coleta de sedimentos de fundo no afluente e no rio Teles Pires. Foram utilizados sacos plásticos de $1 \mathrm{~kg}$ para armazenamento das amostras e etiquetas para identificação do local.

Foi realizado o método de pipetagem (dispersão total em análise Física) com o objetivo de calcular a porcentagem de silte, argila e areia. Para determinação de frações de areia fina, média e grossa foi utilizado o método de peneiramento.

\section{Resultado e Discussão}

O rio Matrinxã está localizado no médio curso da bacia hidrográfica do rio Teles Pires caracteriza-se pela Depressão Interplanáltica da Amazônia Meridional, Planaltos Residuais do Norte de Mato Grosso e Planalto dos Parecis com superfícies de aplanamento com formas tabulares amplas (EPE, 2009). A área de estudo apresenta um perfil de Florestas transicionais, pois encontra-se como divisor de dois biomas importantes: amazônico e o cerrado.

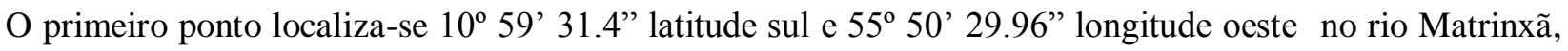
possui $16,2 \mathrm{~m}$ de largura com profundidade de 3,1 m. Registra área de 30,22 $\mathrm{m}^{2} \mathrm{com}$ vazão de 12,5 m³/s (Tabela 1).

Tabela 1. Variáveis Hidrodinâmicas do rio Matrinxã

\begin{tabular}{c|c|c|c|c|c}
\hline PONTO & $\begin{array}{c}\text { LARGURA } \\
(\mathbf{m})\end{array}$ & PROFUNDIDADE $(\mathbf{m})$ & $\begin{array}{c}\text { VELOCIDADE } \\
(\mathbf{m})\end{array}$ & $\begin{array}{c}\text { ÁREA } \\
\left(\mathbf{m}^{2}\right)\end{array}$ & $\begin{array}{c}\text { VAZÃO } \\
\left(\mathbf{m}^{3} / \mathbf{s}\right)\end{array}$ \\
\hline 1 & 16,2 & 3,1 & 0,25 & 50,22 & 12.5 \\
\hline 2 & 383,1 & 3,06 & 0,04 & 1171,98 & 46,87 \\
\hline
\end{tabular}

Após as análises identificou que nenhuma das amostras registrou areia grossa. No entanto, predominou $83,51 \%$ de areia fina, $0,95 \%$ de argila e $15,54 \%$ de silte. Em seguida o centro apresentou 2,34\% de areia média, $57,42 \%$ de areia fina, $2,70 \%$ de argila e $37,54 \%$ de silte. Na margem esquerda do afluente apresentou 55,39\% de areia fina, 13,12\% de argila e 31,49\% de silte (Tabela 2).

Tabela 2. Sedimentos de fundo do afluente

\begin{tabular}{|c|c|c|c|c|c|c|c|c|c|c|c|c|c|c|c|}
\hline \multirow{3}{*}{ Ponto } & \multicolumn{15}{|c|}{ SEDIMENTOS DE FUNDOS \% } \\
\hline & \multicolumn{3}{|c|}{ Areia Grossa } & \multicolumn{3}{|c|}{ Areia Média } & \multicolumn{3}{|c|}{ Areia Fina } & \multicolumn{3}{|c|}{ Argila } & \multicolumn{3}{|c|}{ Silte } \\
\hline & MD & $\mathrm{C}$ & ME & MD & $\mathrm{C}$ & ME & MD & $\mathrm{C}$ & ME & MD & $\mathrm{C}$ & ME & MD & $\mathrm{C}$ & ME \\
\hline
\end{tabular}




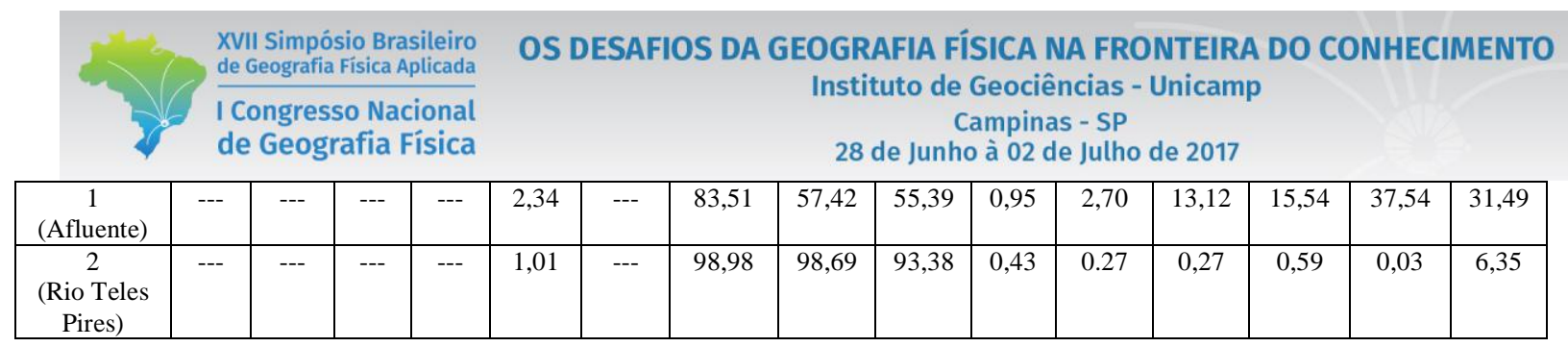

Analisando os dados, o rio Matrinxã tem capacidade de transporte de sedimentos grosseiros. A velocidade do fluxo contribui com o aporte dessa carga sedimentar. Os pesquisadores Feitosa e Santos (2015) ressaltam a importância dos estudos em as áreas de confluência no contexto da geomorfologia fluvial "isso porque representa o somatório de dois ou mais canais", o que revolve toda a unidade de análise da bacia hidrográfica, pois irá abranger os fatores in (dependentes) dos processos geomorfológicos e hidrossedimentológicos com os estudos e interações do clima, vegetação, solo e ação antrópica influenciando o meio.

O segundo ponto encontra-se a $10^{\circ} 59^{\prime} 13.0^{\prime \prime}$ latitude sul e $55^{\circ} 50^{\prime} 32,35^{\prime \prime}$ longitude oeste a jusante do afluente Matrinxã no rio Teles Pires. A área apresenta 1.171,98 m²,383,1 m de largura e profundidade de 3,06 m (Tabela 2). O material de fundo presente na margem direita do rio registrou 98,98\% de areia fina, $0,43 \%$ de argila e $0,59 \%$ de silte. Foi possível quantificar que no centro do canal transporta $1,01 \%$ de areia média, 98,69\% de areia fina, 0,27\% de argila e 0,03\% de silte. Na margem esquerda apresentou 93,38\% de areia fina, $0,27 \%$ de argila e $6,35 \%$ de silte, não sendo constatado areia grossa em nenhuma amostra (Tabela 3). Os dados revelam que ao longo do perfil transversal o rio Teles Pires está transportando sedimentos grosseiros e na margem esquerda continua a tendência de areia fina, confirmando recebimento da carga detrítica do afluente e distribuição dos sedimentos.

\section{Conclusão}

O ambiente de confluência do rio Matrinxã a área de estudo verificou-se um material de fundo com grande porcentagem de areia, somente o centro e a margem esquerda do primeiro ponto registrou uma porcentagem relevante de silte. Não foram apresentados em nenhum dos pontos areia grossa, através das análises contatou-se que a areia média foi encontrada apenas no centro em ambos os pontos. O trabalho afirma que as amostras analisadas são contundentes, pois a carga sedimentar que o rio Teles Pires recebe do afluente influencia na caracterização dos sedimentos e sua distribuição no ambiente de confluência.

\section{Agradecimentos}

Ao projeto "Bacia hidrográfica do rio Teles Pires: dinâmica fluvial e empreendimentos hidroelétricos entre os municípios de Nova Canaã do Norte e Itaúba, Mato Grosso”, financiado pelo Edital 


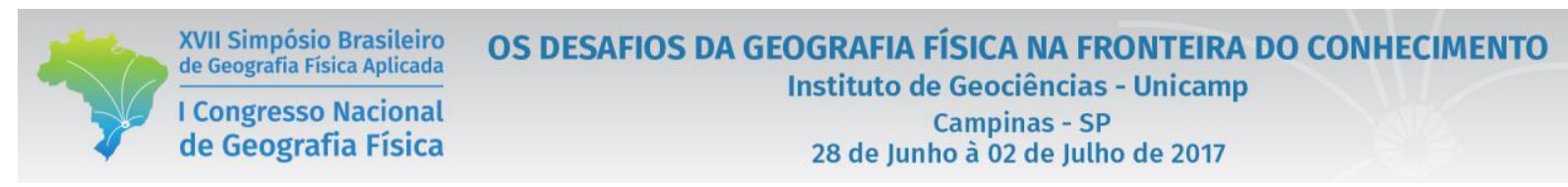

Universal 005/2015 da Fundação de Amparo à Pesquisa do Estado de Mato Grosso - FAPEMAT, pelo apoio financeiro que possibilitou os trabalhos de campo e a sistematização dos dados tratados neste artigo

e pelas bolsas de Iniciação Científica. À Coordenação de Aperfeiçoamento de Pessoal de Nível Superior (CAPES), pela concessão de Bolsa de Institucional de Iniciação a Docência. Também à Universidade do Estado de Mato Grosso (UNEMAT), pelo apoio logístico por meio do Laboratório de Pesquisa e Ensino em Geomorfologia Fluvial (LAPEGEOF) do Campus de Colider.

\section{Referencias}

BARTELLI, GUSTAVO. Estudo do Transporte de Sedimentos em Suspensão na Bacia Hidrográfica do Arroio Garapía - Maquiné- RS. Univates, 2012. Disponivel em:

<https://www.univates.br/bdu/bitstream/10737/311/1/GustavoBartelli.pdf> acesso em: 09 março 2017

CHRISTOFOLETTI, A. Geomorfologia. São Paulo: Blucher, $19802^{a}$ edição.

CUNHA, S. B. "Geomorfologia Fluvial”. In: GUERRA, A. J. T; CUNHA, S. B. da (orgs). Geomorfologia uma atualização de base e conceitos. Rio de Janeiro: Bertrand, 2013.

EMBRAPA, Manual de Métodos de Análise de Solos. Rio de Janeiro: Embrapa solos, $19972^{\text {a }}$ edição.

EPE - Empresa de Pesquisa Energética. Avaliação Ambiental Integrada da Bacia Hidrográfica do Rio Teles Pires. TPI-A-62-000.002-RE-R0, EPE 2008 p.5. Disponível em:

<http://www.epe.gov.br/MeioAmbiente/Documents/AAI\%20Teles\%20Pires/TPI\%20Sumario\%20executivo\%20Car acterizacao.pdf> Acesso em: 06 março 2017

EPE - Empresa de Pesquisa Energética. Avaliação Ambiental Integrada da Bacia Hidrográfica do Rio Teles Pires. Relatório final dezembro 2009. Disponível em: < http://www.epe.gov.br/MeioAmbiente/Documents/AAI\%20Teles\%20Pires/AAI\%20Teles\%20Pires\%20\%20Relat\%C3\%B3rio\%20Final\%20-\%20Sum\%C3\%A1rio\%20Executivo.pdf > Acesso em: 09 março 2017

FEITOSA, G. D. Dos S.; SANTOS, G. B dos. Identificação de geoformas deposicionais em ambiente de confluência dos rios Branco e Grande, região oeste da Bahia: por meio de cálculo de superfície de tendência. Conference: I Congresso Internacional de Hidrossedimentologia. Porto Alegre, Volume: Anais. 2015. Disponível em: :https://www.researchgate.net/publication/309348058. Acesso em: 14 de Fevereiro de 2017.

QUARESMA, SílviaJurema. BONI, Valdete. Aprendendo a entrevistar: como fazer entrevistas em Ciências Sociais. Revista Eletrônica dos Pós-Graduandos em Sociologia Política da UFSC Vol. 2 n 1 janeiro-julho/2005, p. 6880. Disponível em: <https://moodle.ufsc.br/pluginfile.php/1255603/mod_resource/content/0/Aprendendo_a entrevistar.pdf $>$ acesso em: 08 março 2017. 


\begin{tabular}{|c|c|}
\hline $\begin{array}{l}\text { XVII Simpósio Brasileiro } \\
\text { de Geografia Fisica Aplicada } \\
\end{array}$ & $\begin{array}{l}\text { OS DESAFIOS DA GEOGRAFIA FÍSICA NA FRONTEIRA DO CONHECIMENTO } \\
\text { Instituto de Geociências - Unicamp }\end{array}$ \\
\hline $\begin{array}{l}\text { I Congresso Nacional } \\
\text { de Geografia Física }\end{array}$ & $\begin{array}{c}\text { Campinas - SP } \\
28 \text { de Junho à } 02 \text { de Julho de } 2017\end{array}$ \\
\hline
\end{tabular}

SOUSA, C. A. de.(org) Bacia hidrográfica do rio Paraguai-MT: dinâmica das águas, uso e ocupação e degradação ambiental.São Carlos: EditoraCubo, 2012. 